06.5

\title{
Структурное совершенство и состав легированных галлием термомиграционных слоев кремния
}

\author{
(C) А.А. Ломов ${ }^{1}$, Б.М. Середин ${ }^{2}$, С.Ю. Мартюшов ${ }^{3}$, А.Н. Заиченко ${ }^{2}$, С.Г. Симакин ${ }^{4}$, И.Л. Шульпина ${ }^{5}$ \\ ${ }^{1}$ Физико-технологический институт им. К.А. Валиева, Москва, Россия \\ ${ }^{2}$ Южно-Российский государственный политехнический институт (НПИ) им. М.И. Платова, Новочеркасск, Россия \\ ${ }^{3}$ Технологический институт сверхтвердых и новых углеродных материалов, Троицк, Москва, Россия \\ ${ }^{4}$ Ярославский филиал физико-технологического института им. К.А. Валиева, Ярославль, Россия \\ ${ }^{5}$ Физико-технический институт им. А.Ф. Иофрфе РАН, Санкт-Петербург, Россия \\ E-mail: lomov@ftian.ru
}

Поступило в Редакцию 13 декабря 2019г.

В окончательной редакции 13 декабря 2019 г.

Принято к публикации 17 декабря 2019г.

\begin{abstract}
Предложена методика формирования толстых сильно легированных галлием термомиграционных слоев кремния для перспективных приборов силовой электроники. Совершенство структуры и состав слоев в зависимости от температуры их формирования исследованы методами рентгеновской топографии, кривых дифракционного отражения и вторично-ионной масс-спектрометрии. Установлено, что формируемые слои являются монокристаллическими и не содержат на границе с кремниевой подложкой дислокаций несоответствия. Показано, что величину концентрации галлия в слоях можно менять в диапазоне $(1.6-4.8) \cdot 10^{19} \mathrm{~cm}^{-3}$, что выше, чем при легировании кремния алюминием.
\end{abstract}

Ключевые слова: термомиграция, кремний, галлий, дислокации, рентген, дифракция, вторичная ионная масс-спектрометрия.

DOI: 10.21883/PJTF.2020.06.49161.18153

Метод термомиграции (ThM) жидких зон, иначе называемый методом зонной плавки в поле температурного градиента, может быть использован для наращивания сильнолегированных слоев на поверхности полупроводниковых кристаллов [1]. Такие слои толщиной в сотни микрометров востребованы для получения силовых приборов на токи выше 1000 А с низким прямым падением напряжения [2]. В последние годы интерес к этому методу обусловлен возможностями его применения для формирования приборов и структур фотовольтаики, микрои наномеханики, биологических сенсоров $[3,4]$.

Процесс ТhM основан на перекристаллизации кристалла при движении сквозь него зоны растворителя в направлении источника тепла. Наиболее технологически удобной лигатурой для кремния при ТhM является алюминий, позволяющий достичь в слоях кремния концентрации акцепторов в диапазоне $(1-2) \cdot 10^{19} \mathrm{~cm}^{-3}$. Для ряда приложений актуальным является получение слоев с более высокой концентрацией примеси [5]. Это может быть осуществлено за счет использования в качестве лигатуры атомов галлия. Однако комнатная температура плавления галлия затрудняет его использование в процессе термомиграции.

Настоящая работа посвящена отработке режимов легирования галлием кремниевых термомиграционных слоев $\mathrm{Si}(\mathrm{Ga})$, а также изучению их реальной структуры и состава в зависимости от параметров ТhM-процесса. Характеризация образцов проводилась с использованием методов рентгеновской проекционной топографии, двухкристальных кривых отражения и вторично-ионной масс-спектрометрии (ВИМС).

Образцы термомиграционных слоев $\mathrm{Si}(\mathrm{Ga})$ были получены на подложках $\mathrm{Si}(111)$ (удельное сопротивление $10-40 \Omega \cdot \mathrm{cm}$, диаметр $76 \mathrm{~mm}$, толщина $500 \mu \mathrm{m}$ ) $n$ - и $p$-типа проводимости. Концентрация оптически активного кислорода и углерода в кремнии была ниже $10^{18}$ и $10^{17} \mathrm{~cm}^{-3}$ соответственно. Поверхность пластин шлифовалась порошком M14 (F600) и отмывалась по стандартным методикам.

На рис. 1 показаны схема проведения ТhM-процесса (a) и его основные экспериментальные зависимости (b). Для формирования слоев $\mathrm{Si}(\mathrm{Ga})$ были использованы две пластины кремния: подложка и источник (рис. 1,a). Жидкие зоны формировались втягиванием расплавленного $\mathrm{Ga}$ в плоский капилляр, образованный щелью $l$ между двумя пластинами. Наращиваемый на подложке легированный слой формировался из расплава $\mathrm{Ga}-\mathrm{Si}$ при перекристаллизации подтравленного источника. Ширина капилляра $l$ варьировалась в пределах 5-50 $\mu \mathrm{m}$ за счет трех сформированных травлением выступов на периферии источника. Заполнение капиллярной щели галлием и процесс движения расплава $\mathrm{Ga}-\mathrm{Si}$ через источник осуществлялись в вакуумной установке с резистивным нагревом. При отработке стабильных режимов ТhM были определены минимальная толщина капилляра $l_{F}=5 \mu \mathrm{m}$ и пороговая температура $T_{F}=1200 \mathrm{~K}$ процесса заполнения капилляра. Градиент температуры составлял $G \sim 50 \mathrm{~K} / \mathrm{cm}$ и варьировался введением экрана. Оптимальная скорость подъема тем- 

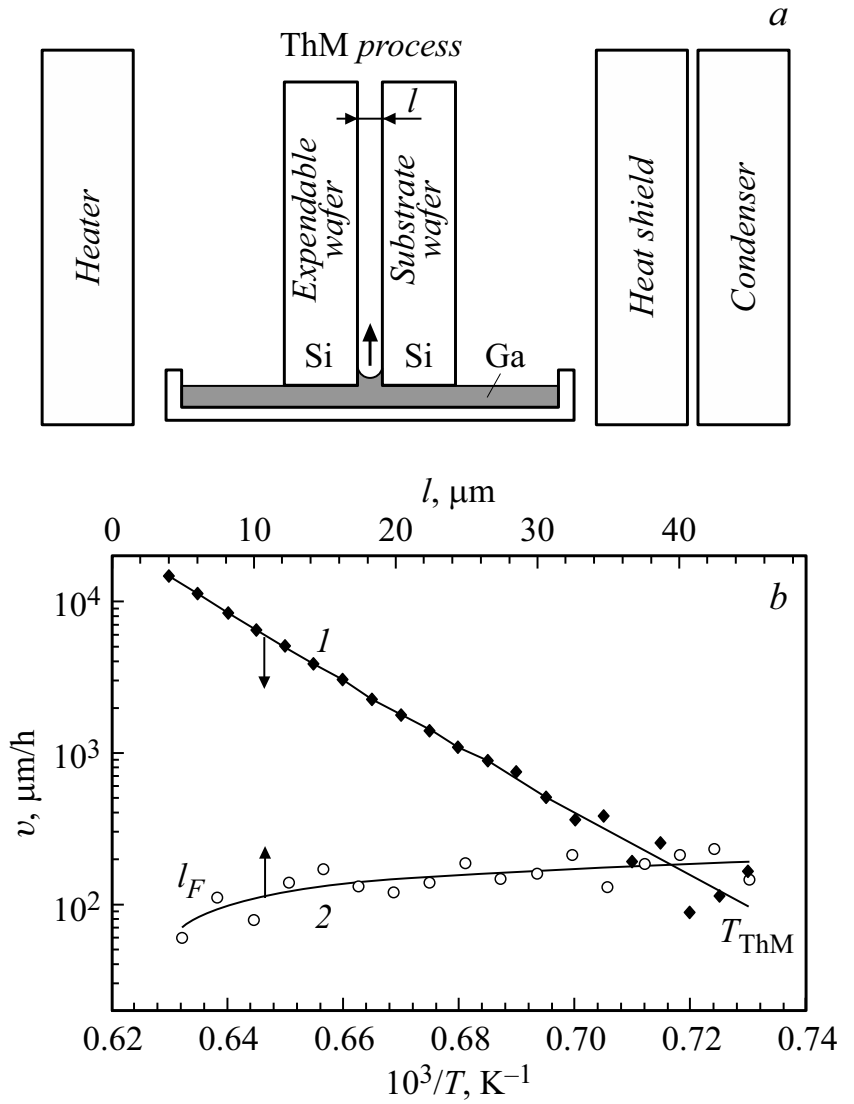

Рис. 1. $a-$ схема формирования ТhМ-слоев. $b-$ экспериментальные зависимости скорости $v$ движения зоны расплава от температуры $T$ (при $l=40 \mu \mathrm{m}, G=50 \mathrm{~K} / \mathrm{cm})(1)$ и от ширины капилляра $l$ (при $1400 \mathrm{~K})(2)$.

пературы пластин от комнатной до рабочей $T_{\mathrm{ThM}}>T_{F}$ составляет $30 \mathrm{~K} / \mathrm{min}$. Толщина слоев $h_{\mathrm{ThM}}$ задавалась временем и скоростью $v$ термомиграции, определенной методом термических импульсов [1].

Зависимости скорости $v$ движения галлиевых жидких зон в кремнии от температуры образца и ширины капилляра показаны на рис. $1, b$. Видно (кривая 1), что скорость процесса экспоненциально зависит от температуры при превышении ее „стартового“ значения $T_{\mathrm{ThM}} \sim 1300 \mathrm{~K}$. При температуре образца ниже $T_{\mathrm{ThM}}$ движения жидкой зоны расплава практически не происходит. Другая особенность движения зоны связана с нелинейной зависимостью ее скорости от ширины капилляра. Из зависимости $v(l)$ (кривая 2) видно, что при постоянной температуре с увеличением ширины капилляра $l$ в диапазоне 5-30 $\mu$ т скорость $v$ растет и сохраняет свое значение только при $l>35 \mu \mathrm{m}$.

Исследования структурного совершенства и состава выращенных слоев $\mathrm{Si}(\mathrm{Ga}) / \mathrm{Si}(111)$ были выполнены на образцах \#G1, \#G2 и \#G3, полученных при температуpax 1400, 1500 и $1600 \mathrm{~K}$ соответственно. Для проведения структурных и спектрометрических исследований слои $\mathrm{Si}(\mathrm{Ga})$ утонялись посредством шлифования и поли- рующего химического травления. На рис. 2 показаны двухкристальные кривые дифракционного отражения в геометрии Брэгга от исследуемых образцов при использовании медного излучения, 333 отражения и плоского монохроматора $\mathrm{Si}(333)$. Видно, что на всех кривых наблюдается два основных максимума, соответствующих отражению от подложки кремния при $\Delta \vartheta=\vartheta-\vartheta_{\mathrm{B}}=0$ $\left(\vartheta_{\mathrm{B}}\right.$ - угол Брэгга) и от легированного галлием слоя со стороны меньших углов. Структурное совершенство образцов может быть оценено по полуширинам (FWHM) соответствующих дифракционных максимумов. Полуширины максимумов как от подложки кремния, так и от легированного галлием слоя увеличиваются для образцов, полученных при более высокой температуре. Например, FWHM максимума от подложки $\mathrm{Si}(111)$ образца \#G1 (кривая 1) равна $4^{\prime \prime}$, что практически соответствует величине FWHM = 3.3" от исходного кремния. А для образца $\# G 3$ (кривая 3) ширина максимума увеличивается в $\sim 3$ раза. Этот результат показывает, что в зависимости от температуры роста слои содержат разное количество структурных дефектов, в частности малоугловых границ, приводящих к мозаичности. Мозаичность образцов обусловлена появлением дислокаций, вызванных релаксацией локализованных термических напряжений. Известно [6], что интенсивное пластическое течение кремния начинается при $T>1200 \mathrm{~K}$. Для процесса термомиграции градиенты температур выбираются равными $G=50-100 \mathrm{~K} / \mathrm{cm}$. Возникающие в пластинах термические напряжения $\sigma=\alpha E G$ (где $\alpha-$ коэффициент теплового расширения, $E-$ модуль Юнга) оказываются достаточными для генерации дислокаций. Для визуализации дислокационной структуры в объеме образцов были получены рентгеновские топограммы в геометрии прохождения по методу Ланга как от исходных пластин кремния, так и от полученных образцов. Анализ топограмм от исходных пластин подтвердил отсутствие в них дислокаций.

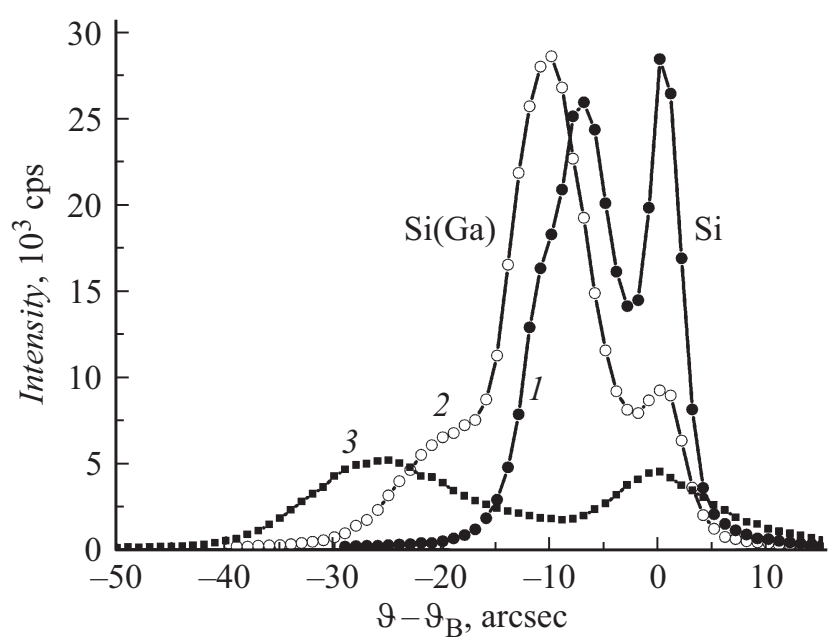

Рис. 2. Кривые дифракционного отражения от термомиграционных слоев $\mathrm{Si}(\mathrm{Ga}) / \mathrm{Si}(111)$, полученных при температурах 1400 (1), 1500 (2), $1600 \mathrm{~K}(3)$. 
Ростовые и структурные параметры термомиграционных слоев $\operatorname{Si}(\mathrm{Ga})$ толщиной $h_{\mathrm{ThM}}$ на подложке $\operatorname{Si}(111)$

\begin{tabular}{c|c|c|c|c|c|c}
\hline Образец & $\begin{array}{c}\mathrm{Si}(111), \\
\text { примесь }\end{array}$ & $\begin{array}{c}T_{\mathrm{ThM}}, \\
\mathrm{K}\end{array}$ & $\begin{array}{c}h_{\mathrm{ThM}}, \\
\mu \mathrm{m}\end{array}$ & $\begin{array}{c}C_{\mathrm{Si}}^{\mathrm{Ga}} \\
10^{19} \mathrm{~cm}^{-3} \\
(\mathrm{BHMC})\end{array}$ & $\begin{array}{c}\Delta d / d, \\
10^{-5}\end{array}$ & $\begin{array}{c}C_{\mathrm{Si}}^{\mathrm{Ga}}, \\
10^{19} \mathrm{~cm}^{-3} \\
(X \text {-ray })\end{array}$ \\
\hline$\# G 1$ & $\mathrm{P}\left(2 \cdot 10^{14} \mathrm{~cm}^{-3}\right)$ & 1400 & $\sim 20$ & $1.6(2)$ & $\langle 4.0\rangle$ & $\sim 1.6$ \\
$\# G 2$ & $\mathrm{P}\left(2 \cdot 10^{14} \mathrm{~cm}^{-3}\right)$ & 1500 & $\sim 5$ & $2.5(3)$ & $\langle 5.7\rangle$ & $\sim 2.3$ \\
$\# G 3$ & $\mathrm{~B}\left(1 \cdot 10^{15} \mathrm{~cm}^{-3}\right)$ & 1600 & $\sim 40$ & $4-7$ & $12(1)$ & $\sim 4.8$
\end{tabular}

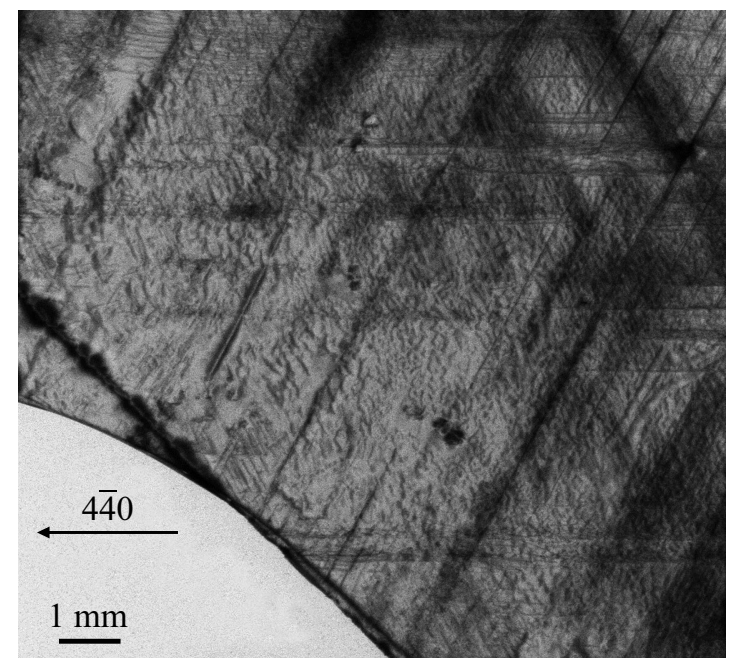

Рис. 3. Рентгеновская топограмма по методу Ланга для образца $\mathrm{Si}(\mathrm{Ga}) / \mathrm{Si}(\# G 2)$, полученного методом ТhM при $1500 \mathrm{~K}$. $\operatorname{Ag} K_{\alpha 1}$-излучение.

На рис. 3 представлена проекционная рентгеновская топограмма образца \#G2 при использовании излучения серебряного анода $(\lambda=0.56 \AA)$. Параметр съемки $\mu h_{\mathrm{ThM}}=0.36$, где $\mu=8 \mathrm{~cm}^{-1}$ - линейный коэффициент фотоэлектрического поглощения. На топограмме присутствует большое количество изображений полос скольжения в направлениях $\langle 110\rangle$ и отдельных дислокаций между ними. Распределение дислокаций крайне неравномерно. В некоторых областях образца наблюдаются лишь короткие криволинейные дислокации. В полосах плотность дислокаций увеличена, наблюдается тенденция перерождения полос в малоугловые границы. Образование этих дефектов подтверждает релаксацию локализованных термических напряжений, что необходимо учитывать при выборе режимов ТhM. В то же время характерных изображений дислокаций несоответствия на топограмме (рис. 3), а также на топограммах образцов $\# G 1$ и $\# G 3$ не наблюдается. Отсутствие этих дислокаций связано с малым значением относительной деформации $\Delta d / d=-\operatorname{ctg} \vartheta_{\mathrm{B}} \cdot \Delta \vartheta \sim 10^{-5}$ кристаллической решетки слоя $\mathrm{Si}(\mathrm{Ga})$ из-за близости величин ковалентных радиусов атомов кремния и галлия [7]. C увеличением температуры ThM деформация слоя $\mathrm{Si}(\mathrm{Ga})$ возрастает пропорционально количеству атомов галлия, вошедших в решетку кремния в позиции замещения.

Для определения состава и величины концентрации галлия в слое $\mathrm{Si}(\mathrm{Ga})$ образцов были проведены исследования методом ВИМС. Измерения проводились с помощью зондирования ионами $\mathrm{Bi}^{3+}$ с энергией $25 \mathrm{keV}$ в режиме динамической фокусировки пакетов по времени при диаметре зонда на поверхности образца $10 \mu \mathrm{m}$. Концентрация галлия $C_{\mathrm{Si}}^{\mathrm{Ga}}$ (см. таблицу, столбец ВИМС) была определена на основе коэффициентов относительной чувствительности для стандартных образцов.

Результаты ВИМС не показывают различия элементного состава при разной температуре формирования ThM-слоя для исследуемых образцов. Однако кроме основных элементов ${ }^{28} \mathrm{Si},{ }^{30} \mathrm{Si}$ и ${ }^{69} \mathrm{Ga}$ как вблизи поверхности, так и в глубине слоев были обнаружены атомы ${ }^{115} \mathrm{In}$. Индий аналогично галлию является элементом III группы и может входить в решетку кремния в позиции замещения. Установлено, что коэффициенты относительной чувствительности для галлия и индия практически равны. Этот факт позволил оценить концентрацию $C_{\mathrm{Si}}^{\mathrm{In}}$ в слоях как 10 at.\% от содержания галлия.

Рентгенодифракционные данные о величинах деформации слоев $\mathrm{Si}(\mathrm{Ga})$ позволяют оценить концентрацию атомов галлия $C_{\mathrm{Si}}^{\mathrm{Ga} *}$ (см. таблицу, столбец $X$-ray) в кристаллической решетке в позиции замещения. Расчет концентраций величин $C_{\mathrm{Si}}^{\mathrm{Ga} *}$ был выполнен на основе закона Вегарда в приближении модели [8] упругих деформаций. Учет деформации решетки слоев из-за присутствия атомов индия был выполнен в линейном приближении. Тогда концентрация галлия будет определяться как $C_{\mathrm{Si}}^{\mathrm{Ga} *}=K(\Delta d / d)\left(1 /\left\langle\beta_{\mathrm{Ga}}\right\rangle\right)$, где $\beta_{\mathrm{In}, \mathrm{Ga}}=\left(1 /\left(3 C_{\mathrm{Si}}^{s}\right)\right)\left[\left(r_{\mathrm{Ga}, \mathrm{In}} / r_{\mathrm{Si}}\right)^{3}-1\right], \quad K \approx 0.695 \quad[8]$ для $\mathrm{Si}(111), \quad r_{\mathrm{Si}}=0.117 \mathrm{~nm}, \quad r_{\mathrm{Ga}}=0.126 \mathrm{~nm} \quad$ и $r_{\mathrm{In}}=0.144 \mathrm{~nm}-$ ковалентные радиусы атомов кремния, галлия и индия соответственно [7].

Таким образом, использование в ТhМ галлиевых зон позволяет получать толстые монокристаллические слои кремния с более высокой концентрацией акцепторов, чем при легировании кремния алюминием.

\section{Финансирование работы}

Работа выполнена в рамках государственного задания ФТИАН им. К.А. Валиева РАН по теме № 0066-2019-0004 и ФТИ им. А.Ф. Иоффе РАН по теме 
№ 9-16 0040-2019-0016, а также частично поддержана Российским фондом фундаментальных исследований (грант № 19-07-00306).

\section{Конфликт интересов}

Авторы заявляют, что у них нет конфликта интересов.

\section{Список литературы}

[1] Лозовский В.Н., Лунин Л.С., Попов В.П. Зонная перекристаллизация градиентом температуры полупроводниковых материалов. М.: Металлургия, 1987. 232 с.

[2] Лозовский В.Н., Лунин Л.С., Середин Б.М. // Изв. вузов. Электромеханика. 2015. № 5(541). С. 54-58.

[3] Schmit R.R., Gee J.M. Emitter wrap-through back contact solar cells on thin silicon wafers. Patent US № 7649141. Date of Patent: 19.01.2010.

[4] Eslamiem M., Saghir M.Z. // Fluid Dyn. Mater. Process. 2012. V. 8. N 4. P. 353-380.

[5] Мнацаканов T.T., Левинштейн М.Е., Шуман В.Б., Середин Б.М. // ФТП. 2017. Т. 51. В. 6. С. 830-834.

[6] Концевой Ю.А., Литвинов Ю.М., Фаттахов Э.С. Пластичность и прочность полупроводниковых материалов и структур. М.: Радио и связь, 1982. 240 с.

[7] Pyykko P. // Phys. Rev. B. 2012. V. 85. N 2. P. 024115 (1-7).

[8] Hornstra J., Bartels W.J. // J. Cryst. Grwth. 1978. V. 44. N 5. P. 513-517. 